\title{
Cultura de organizações públicas de saúde - notas sobre a construção de um objeto
}

\author{
The culture of public health organizations: \\ notes on the construction of an object
}

Jeni Vaitsman 1

\footnotetext{
1 Departamento de Ciências Sociais, Escola Nacional de Saúde Pública, Fundação Oswal do Cruz. Rua Leopoldo Bulhões 1480 9 o andar, Rio de Janeiro, RJ 21041-210, Brasil. vaitsman@ensp.fiocruz.br
}

Abstract The author defines some central concepts for construction of the subject of "public heal th organizations". The concept of culture is exceedingly broad, and must be adjusted to the types of particular phenomena analyzed. As perceived in a public health organization, culture implies phenomena belonging to different social dimensions and which can be grasped through the concepts of political, civic, organizational, and professional culture.

Key words Culture; Organizations; Health

Resumo Nestas notas, defino alguns conceitos necessários para a construção do objeto "cultura de organizações públi cas de saú de". O concei to de cultura é amplo e deve ser aj ustado aos tipos defenômenos parti culares que se pretende anal isar. Tal como é percebi da em uma organização pública de saúde, a cultura implica uma imbricação de fenômenos de distintas ordens, analisados mediante os conceitos de cultura política, cultura cívica, cultura organizacional e cultura profissional.

Palavras-chave Cultura; Organizações; Saúde 
Nestas notas, faço al gumas reflexões a respeito de questões conceituais relativas à construção do objeto "cultura de organizações públicas de saúde", no projeto "Cultura Organizacional e Mudança: uma análise dos processos de reestruturação organizacional em instituições públicas de saúde". O projeto faz parte da linha de investigação Aval iação e Desempenho dePolíticas Públi cas da Escola Nacional de Saúde Pública (ENSP) e pretende incorporar a dimensão cultural na análise das mudanças organizacionais, as quais vêm sendo propostas e/ ou implementadas no setor saúde como parte do processo de reforma do Estado.

A partir da última década, vem-se procurando trazer para a administração pública brasileira a idéia de revolução gerencial que ocorreu na administração de empresas por meio da flexibilização, da descentralização dos processos de decisão e trabalho, do controle de resultados, em lugar do controle de processos e da ênfase na qualidade e eficiência dos serviços prestados. Esta concepção - desenvolvida para o contexto norte-americano principalmente por Osborne \& Gaebler (1992) - parte do princípio de que os servidores públicos teriam algumas características, tais como: competência para se autogerir, autonomia, iniciativa, responsabilidade e comprometimento com a coisa pública.

O gerencialismo na administração pública pressuporia a substituição das práticas e valores tradicionais, particularistas, por outras que, combinadas ao universalismo explícito na concepção de Estado moderno, alcançassem eficiência e eficácia. Isso também suporia uma mudança na relação entre os agentes do estado e os da sociedade, ou seja, dos sujeitos que representam estas duas entidades nos momentos em que elas interagem em distintos contextos. Em uma situação ideal, teríamos, por um lado, servidores/ prestadores de serviços responsáveis e passíveis de responsabilização e, por outro, cidadãos cuja consciência em relação aos custos dos serviços e aos direitos tivesse, como contrapartida, instituições que garantissem o exercício efetivo desses direitos.

O fato de estarmos longe dessa situação ideal requer pesquisas com diferentes focos, mas, a meu ver, qualquer análise que pretenda apreender a relação entre a proposta gerencialista e o que existe de específico em organizações públicas de saúde não deveria prescindir de uma abordagem interdisciplinar ou mesmo transdisciplinar. Do ponto de vista estritamente disciplinar, os fenômenos que se passam no interior de uma organização de saúde são atravessados por distintos campos de conheci- mento e domínios teóricos; um modo de abordar os problemas de forma complexa seria pensá-los a partir da articulação de conceitos da História, Sociologia, Antropologia, Ciência Política, Administração etc. Contudo, as ‘organizações públicas de saúde' não são nosso objeto, mas sua cultura, o que recorta e, ao mesmo tempo, desdobra o escopo da análise, uma vez que cultura pode se referir a várias dimensões do simbólico. Esta categoria, que já possui toda uma tradição na área da saúde - como, por exemplo, no campo da antropologia médica, do estudo de endemias e representações sobre saúde-doença - vem sendo bastante utilizada quando se fala de organizações e instituições como uma espécie de chave polissêmica que nem sempre discrimina os fenômenos aos quais está sendo aplicada.

Não existe uma única definição de cultura, ainda mais porque, em se tratando de conceito que se institui como eixo disciplinar da Antropologia, suas definições vêm acompanhando as próprias transformações e disputas no interior do campo. Mas se entendemos por cultura um sistema de significados que cria algum tipo de identidade compartilhada (Geertz, 1989), uma espécie de código que orienta as práticas sociais de pessoas pertencentes a vários grupos e categorias sociais dentro de uma sociedade, essa definição mais ampla deve ser ajustada aos tipos de fenômenos particulares que se pretende analisar. É possível recortar os fenômenos ou problemas relativos à cultura em uma organização pública de saúde, a partir de sua pertinência a distintas dimensões, tais como cultura política, cultura cívica, cultura organizacional e cultura profissional. Vejamos os elementos do mundo social que podem ser apreendidos por estes conceitos.

Se cultura política refere-se ao conjunto de códigos, valores, regras não escritas que orientam as práticas políticas de determinado grupo ou sociedade, por cultura cívica podemos entender os valores, crenças e atitudes em relação aos direitos e deveres de cidadania nessa sociedade. Cultura cívica diz respeito, por conseguinte, à confiança das pessoas em relação às intenções e ações de governantes e dirigentes, bem como suas representações a respeito de como funcionam as relações entre coisa pública e sociedade. Desse modo, constitui uma dimensão que se produz a partir da própria experiência e da percepção de como operam as práticas políticas na sociedade.

Apesar dos elementos agregados para formar estes conceitos - sejam eles práticas observadas, palavras sob a forma de discursos comuns ou os mais diversos tipos de dados - po- 
derem ser analiticamente diferenciados enquanto distintas dimensões da cultura, tais elementos resultam de uma mesma matriz sóciohistórica, de um mesmo processo de constituição das instituições políticas e sociais. Ambos os conceitos referem-se a sistemas de significados que atravessam práticas e valores orientados a fins que podem ser diferenciados, porém articulam-se no interior dos sujeitos e imbricam-se na constituição de práticas políticas e sociais, na institucionalização da coisa pública, nas relações entre estado e sociedade. Consistem em uma espécie de substrato simbólico, pano de fundo invisível orientando as ações dos atores - individuais e coletivos - que interagem nos diversos espaços sociais, entre os quais, as organizações públicas.

Produto de uma história social, política e cívica, a configuração de qualquer organização pública também revela determinado padrão de interações entre seus membros. Se, por cultura organizacional, entendemos o sistema de significados compartilhados pelos membros de uma organização, que Ihes dá algum tipo de identidade coletiva, a cultura das organizações públicas é marcada pelo modo como se instituíram as relações entre estado e sociedade, bem como as relações do sujeito com a coisa pública.

Para muitos autores, falar em cultura organizacional é considerar uma organização como uma espécie de "minissociedade", que construiu um sistema de significados (Ott, 1989). A cultura de uma organização seria algo conformado por coisas como valores, crenças, pressupostos, percepções, normas e padrões de comportamento não muito pal páveis e tampouco fáceis de serem observadas e apreendidas, embora tomadas como óbvias. Constituiriam uma força subjacente, movendo e configurando as práticas organizacionais e mobilizando seus membros para agir em certas direções.

Mas, certamente, esta minissociedade está dentro de uma sociedade maior e, assim, a cultura de qualquer organização, se é resultado, por um lado, da teia de relações instituídas ao longo de sua própria história enquanto organização, também comporta elementos da cultura da sociedade em que está inserida, aí incluídas suas dimensões política e cívica.

O pertencimento a uma organização pública de saúde implica al gum tipo de identidade coletiva, dada pela característica do público e da saúde. Um dos elementos definidores dessa identidade é o fato das atividades dos membros da organização estarem voltadas para o enfrentamento de fenômenos de vida e morte, ou, falando de outro modo, para a produção de bens e/ ou serviços para a promoção do bem- estar físico, mental e social de seus usuários/ clientes. Diferentes tipos de organizações de saúde possuem lógicas específicas, mas todas elas compartilham al gumas características semelhantes, como, por exemplo, a autonomia dos médicos e a centralidade de seu lugar na hierarquia organizacional.

Pertencer a uma organização pública de saúde certamente constitui elemento de identidade, mas não o único. Um dos critérios de diferenciação interna é o fato das pessoas fazerem parte de distintas categorias ou grupos profissionais, bem como de setores e departamentos voltados para determinados tipos de atividades. As habilidades aprendidas, os conhecimentos, práticas e valores próprios das profissões e/ ou ocupações que convivem no local de trabalho, envolvem a existência de vários sistemas de significados e hierarquias de poder que operam simultaneamente, articulando-se ou não, estabelecendo vários tipos de conflito e produzindo uma certa gestalt organizacional.

Aqui entramos no terreno da cultura não como um sistema de significados unificado, mas como uma espécie de mosaico em que vários mundos prático-simbólicos coexistem em nossa sociedade complexa e fragmentada. A cultura de uma organização - se ainda pudermos fazer referência a esse conceito no singular -, tal como observada em um corte sincrônico, apresenta-se como momento de um processo diacrônico com múltiplas dimensões. Cultura refere-se à tradição, ou seja, à reprodução de significados e padrões de comportamentos através do tempo. A tradição é transmitida pela cultura e sua persistência reside no fato de ser incorporada inconscientemente por intermédio da história social e individual, traduzindo-se nos habitus, valores e representações sociais.

A cultura, contudo, não se reproduz independentemente das condições que a produzem. Nas sociedades e/ ou situações tradicionais, as possibilidades de escolhas e padrões são limitadas: as pessoas fazem as coisas como elas sempre foram feitas e os comportamentos são legitimados em nome da própria tradição, o que limita a mudança e o surgimento de novos padrões sociais. Já nas sociedades contemporâneas, marcadas por reflexividade (Beck, 1995), embora as tradições não desapareçam, elas devem ser justificadas diante de outros modos de se comportar ou fazer as coisas. Isto acaba produzindo não apenas conflitos, mas novos padrões de comportamento e mudanças no próprio sistema de significados, ou seja, na cultura. O problema é que, em virtude de os códigos culturais "anteriores" não desaparecerem, permanecendo subjacentes e orientando 
os comportamentos, a relação entre permanência e mudança é sempre incerta, inesperada e mesmo paradoxal.

Este é um dos dilemas que se colocam para a introdução das propostas reformadoras nas organizações públicas de saúde e leva a outra questão metodológica: a análise da relação entre, de um lado, novos desenhos institucionais e/ ou inovações gerenciais e, de outro, mudanças na cultura de organizações públicas de saúde, as quais só podem ser feitas com base em

\section{Agradecimentos}

O projeto recebeu o apoio do Conselho Nacional de Desenvolvimento Científico e Tecnológico (CNPq) e da Fundação de Amparo à Pesquisa do Estado do Rio de Janeiro (FAPERJ). metodologia que permita a verificação da reprodução ou não de certos padrões ao longo do tempo.

Portanto, além da construção do objeto por meio de uma articulação conceitual em que se apreendam distintas ordens de fenômenos, a elaboração de indicadores de mudanças culturais e sua sistematização mediante índices capazes de acompanhar o sentido dessas mudanças é outro desafio que se apresenta à continuidade deste projeto.

\section{Referências}

BECK, U., 1995. The reinvention of politics: Towards a theory of reflexive modernization. In: Reflexive Modernization (U. Beck, A. Giddens \& S. Lash, eds.), pp. 1-55, Cambridge: Polity Press.

GEERTZ, C., 1989. A Interpretação das Culturas. Rio de Janeiro: LTC Editora.

OSBORNE, D. \& GAEBLER, T., 1992. Reinventing Government. Reading: Addison-Wesley.

OTT, S., 1989. The Organizational Culture Perspective Pacific Grove: Brooks/Cole Publishing Company. 